\title{
Research about the Effect of Company Name on Investor Recognition and Company Value
}

\author{
Yuqi Deng ${ }^{1, a}$ and Yan Zhou ${ }^{1}$ \\ ${ }^{1}$ Nanjing University of Science and Technology, School of Economics and Management, 210094 Nanjing, China
}

\begin{abstract}
In order to study the impact of company name on investor recognition and company value, this article constructs a set of evaluation system of the company name according to the Chinese way about thinking and Chinese characters from the terseness, smooth, moral and recognition, then I grade the listed companies. This article makes the comprehensive evaluation on behalf of the company name, the number of shareholders, the average number of shares hold by an owner and the institutional investors holding on behalf of the investor recognition, then makes the tobin's Q and price-to-book on behalf of the company value. Afterwards, this article sets up a fixed effect panel regression model. The empirical research shows that: if the company's name is concise, easy to pronounce, easy to remember and has a good moral, the company will have the higher investor recognition, and higher valuations.
\end{abstract}

\section{Introduction}

\subsection{Research background}

We are in the Internet era and information is very fast, massive, and complicated. So investors cannot handle too much information in a short time. It is difficult to find a suitable stock for most investors who do not have professional information channels. According to traditional financial theory, stocks or company names that do not contain company fundamentals information don't affect share prices. But behavioural finance believes that investors usually have cognitive biases when investing in stocks, and they are often influenced by instinct to simplify the decision-making process. When faced with risks, investors prefer to choose familiar stocks or familiar company to avoid. People always prefer something whose name is smooth and short, and they always like what they are familiar with and are impressed with, because such things can make people want to be close, resulting in their love of them. Pensa ranks company names according to the criteria of whether it is smooth, easy to remember and pronounce. Online survey shows that companies with good names are more popular with survey respondents. Most respondents believe that companies with higher rankings are more valuable ${ }^{[1]}$.

In stock market, lots of retail investors lack professional experience and information channels. This phenomenon will cause market sentiment to show systemic deviations, such as the herding effect exhibited by investors in China's stock market. However, relatively rational institutional investors will also be affected by the company name. This phenomenon not only affects the investor recognition, but also affects the companies.

a Yuqi Deng: 89717865@qq.com

\subsection{Literature review}

\subsubsection{The effect of company name on investor recognition}

In securities market, most investors do not have reliable information channels and professional knowledge. When choosing stocks, they will be disturbed by the literal meaning of the company's name and make wrong decisions. If the company name is short, fluent, easy to identify and contains good moral meaning, the company will be favoured by investors. Qiao proved through empirical analysis that the stock with the word "China" is indeed more attractive to investors ${ }^{[2]}$. Oppenheimer believes that short names are easier to remember than longer ones. The short names make people more positive and more favoured ${ }^{[3]}$. Alter and Oppenheimer confirmed that companies with well-known names will attract more attention from investors when considering company performance $e^{[4]}$. Huang, Fan and Zhou found that brand have a significant impact on consumers' attitude, quality perception, and purchase intention through intergroup experiment ${ }^{[5]}$. Bao et al. found that products with easy-topronounce names have higher brand recognition ${ }^{[6]}$. Green and Jame pointed out that companies with simple, short, fluent and easy-to-pronounce names have more investors and higher stock turnover ${ }^{[7]}$. Fang discovered that the cognitive difficulty and the meaning about the stock name would be affected by the stock rebranding event, and then changed the degree of investor attention to $\mathrm{it}^{[8]}$. Liu found out through the questionnaire survey data that newly opened investors lacked experience. When 
investing in stocks, they would be affected by the stock names. Experienced investors would use more professional knowledge, rational minds, and accumulated experience to invest ${ }^{[9]}$. The company name has a greater impact on small and medium investors.

\subsubsection{The effect of company name on company value}

Cooper et al. found that if the company added ".com" to the name after the Internet broke out, the stock price will increase abnormally ${ }^{[10]}$. Head et al. find that companies whose names are known by most people are more profitable than market portfolios ${ }^{[11]}$. Liu and Tian confirmed that the stock price will rise abnormally in the announcement day of stock name change ${ }^{[12]}$. Liu found out through the survey data that the clarity of the name's meaning will affect the stock price on the first day of stock issuance and afterwards, and this phenomenon will disappear after a long time ${ }^{[9]}$. Li et al. found that stocks with similar names have a high positive correlation between their yields ${ }^{[13]}$.

\subsubsection{The effect of investor recognition on company value}

Dai discovered that under the incident research window ($1,+1)$, some companies whose stock names changed may be affected by the stock rename event ${ }^{[14]}$. Yu and Zhang conducted an empirical study with Baidu Index as an indicator of interest and found that the degree of investor concern will affect the company's stock price ${ }^{[15]}$.

\subsubsection{Relevant research status}

In recent years, the influence of the stock name on the stock price has gradually been concerned by many domestic scholars, but there is no systematic evaluation system for the fluency of the name. We can't analyse quantitatively. It is difficult to guarantee the objectivity of the scores by questionnaire survey. Measuring the stock abbreviation by 0 point, 1 point, and 2 points is too general, and the research results lack reliability. Most scholars in China are committed to the influence of stock abbreviation. They rarely study the company's name. The abbreviation of the stock is too simple and contains less information. The company name is longer and contains more information, which can more fully reflect the company's specific situation.

Foreign scholars have established a name scoring system for the fluency of company names, the system is complete, and it is suitable for foreign companies, but it can't be used to score the names of Chinese listed companies. The names of Chinese listed companies are made up of Chinese characters. Moreover the Chinese people's thinking methods are different from foreigners. The pronunciation and meaning of Chinese characters are also different from foreign languages.

\subsection{Main content and research methods}

Section 2 constructs a set of evaluation system of the company name according to the Chinese way about thinking and Chinese characters from the terseness, smooth, moral and recognition, and scores the names of listed companies. Section 3 is an empirical study of the impact of company name on investor recognition and company value. Section 4 concludes.

\section{Company name evaluation system}

The company name represents the company's image. A good company name will form a brand effect, which virtually brings a lot of economic value to the company. Chinese company names generally consist of administrative division, brand, industry characteristic and organizational form. For example, "Zhengzhou + Yutong + Bus + Co., Ltd.". Investors tend to automatically filter out redundant information when they contact with company names. Therefore, this paper removes suffixes (e.g., stock companies, companies, and corporations) and administrative division levels (e.g., provinces and cities) in company names. When Green and Jame measure the fluency of the company's name, the fluency of the company name's pronunciation is judged by checking whether all the words in the company name can pass the spell check filter ${ }^{[7]}$. Measuring the fluency of Chinese company names obviously can't be like researching English words. Instead, it should examine the pronunciation, meaning and appearance of Chinese characters. When an investor receives information, it often divides the information into familiar the single word or multi-words for comprehension. So, according to the Chinese way about thinking and Chinese characters, this paper divides the company name into "minimum information unit", which belongs to the main term and some unlisted proper nouns included in the latest edition of "Modern Chinese Dictionary" (i.e., the 7th edition). The "minimum information units" are separated by commas. For example, "Zhengzhou Yutong Bus Co., Ltd." should be divided into "Zhengzhou, Yutong, Bus".

Short name will impress investors, speed up information processing speed. Fluent name more easily accepted by investors. Words that convey positive, good information will make investors react positively and be loved. In addition, when dealing with information, people will skip more unfamiliar words or dilute the impression of such words, so investors prefer the names of easily identifiable investees. In summary, this paper will score the company name from four aspects: terseness, smooth, moral and recognition. The number of "minimum information unit" in the adjusted company name is $\mathrm{k}$. The number of single word "minimum information unit" is $\mathrm{m}$, which represents people's beautiful pursuit and desire and the number of "minimum information unit" extolling virtues is $u$. The Terseness index of the company name is $1 / \mathrm{k}$, the Smooth index is $1 /(1+\mathrm{m})$, and the Moral index is $\mathrm{u}$. In this paper, the Recognition index is measured by the relative frequency of use of the "minimum information unit" in the Center for Chinese Linguistics Peking University abbreviated as CCL. With the progress of the times, the development of domestic corpora is on the rise. 
In 2000, the CCL established by the Institute of Computational Linguistics of Peking University have a very wide coverage and large scale. Zhang believes that the CCL has a wide coverage and reasonable sampling distribution, which truly reflects the development of modern China $^{[16]}$. It can be seen that the relative frequency of use in CCL can objectively demonstrate people's familiarity with this corpus.

This paper examines the Recognition index from three aspects: place name, brand and industry information in company name, which are defined as District Freq, Brand Freq and Industry Freq. We define them as follows:

$$
\text { District Freq }=\frac{F\left(B_{1} B_{2}\right)}{F(\text { Beijing })}
$$

$$
\text { Brand Freq }=\left[\frac{F\left(B_{1}\right)}{F(D e)} \times \frac{F\left(B_{2}\right)}{F(D e)} \times \ldots \times \frac{F\left(B_{j-l} B_{j}\right)}{F(\text { Fazhan })}\right]^{1 / \mathrm{p}}
$$

Industry Freq $=\left[\frac{F\left(H_{l}\right)}{F(\text { Dian })} \times \frac{F\left(H_{2}\right)}{F(\text { Dian })} \times \ldots \times \frac{F\left(H_{j-l} H_{j}\right)}{F(\text { Nongye })}\right]^{1 / \mathrm{q}}$

$$
\begin{gathered}
\text { Name Score }=\text { Terseness }+ \text { Smooth }+ \text { Moral }+ \text { District } \\
\text { Freq }+ \text { Brand Freq }+ \text { Industry Freq }
\end{gathered}
$$

And $B_{1} B_{2}$ is the name of the lowest administrative division in the company name, as most investors will give priority to it; $F\left(B_{1} B_{2}\right)$ is the record number in CCL. $F\left(B_{i}\right) / F(D e)$ and $F\left(B j_{-I} B_{j}\right) / F($ Fazhan $)$ respectively indicate the relative frequency of use of the single word and multi-words "minimum information unit" in the brand, and $p$ is the number of "minimum information unit" in the brand. $F\left(H_{i}\right) / F($ Dian $)$ and $F(H j-$ $\left.{ }_{1} H_{j}\right) / F$ (Nongye) respectively indicate the relative frequency of use of the single word and multi-words "minimum information unit" in the industry information, and $q$ is the number of "minimum information unit" in the industry information. In order to reduce the skewness and kurtosis of the index, make the median and mean of different index close and reduce the impact of different weightings when different indices are added together, this paper makes the Terseness, Smooth, and Moral scores become Min-max normalization data, then extracts the square root of them. Afterwards this paper makes the District Freq, Brand Freq and Industry Freq scores become Min-max normalization data, finally extracts the fourth root of them. The sum of the final data is Name Score.

\section{Empirical research}

\subsection{Theoretical hypothesis}

People always prefer something whose name is smooth and short, and they always like what they are familiar with and are impressed with, because such things can make people want to be close, resulting in their love of them. Merton believes that investors have different information on different securities, and they always invest in securities they are familiar with. In this paper, the number of shareholders represents the preference of small and medium investors for stock companies. Institutional investors are more cautious and their investment is more dispersed. So, institutional investors will increase the proportion of investment when they favour this stock. Therefore, this paper proposes the first hypothesis that if the company name is short, fluent, easy to identify and contains good moral meaning, the company will have more investors, higher per capita shares and institutional investors.

When companies are favoured by investors, the demand for company stocks will increase, and stock price will rise, the company value will increase. The greater the liquidity of the stock, the lower its trading risk. Low risk will be accompanied by a lower required rate of return, and the company's value will increase accordingly. Therefore, this paper proposes the second hypothesis that if the company name is short, fluent, easy to identify and contains good moral meaning, the company will be more valuable.

\subsection{Data and variable construction}

We select the A shares of non-financial listed companies listed on the Main Board at least one year from 1992 to 2011. Then exclude the following company sample: Company whose name contains the name of school, institute, people and parent company; Company whose name only contains geographical and industrial information; Company whose name contains "Guoji", "Zhongguo", "Shijie", "Guojia", "Huaxia", "Jiuzhou", "Quanguo", "Zhonghua", "Shenzhou", "Wuzhou", "Huanqiu"; Company whose name doesn't include company location information, and the brand is just an ordinal number; Company whose name contains English abbreviations and Arabic numbers; Company which was marked as ST, *ST, SST, S*ST, PT in the inspection year.

Rating of sample company name according to established company name evaluation system, we get the Name Score. To verify the first hypothesis, we construct the variable Shareholders, Avg Share and Inst Share are respectively $\ln \left(\mathrm{n}_{1}\right), \ln \left(\mathrm{n}_{2}+1\right), \ln \left(\mathrm{n}_{3}+1\right)$, and $\mathrm{n}_{1}$ is the number of shareholders at the end of the year, $\mathrm{n}_{2}$ is per capita shares, $\mathrm{n}_{3}$ is the percentage of shares held by institutional investors in total shares. Companies with large operating scales will allow investors to think that they are more reliable. So we construct Size as a control variable, which is the 10-logarithmic value of the yearend total market value (in millions). The transaction costs also affect the investor's willingness to hold shares, therefore we construct the control variable Turnover, which is the monthly average turnover rate of the stock during the year. Moreover, we construct the control variable Age which is the natural logarithm of the number of months that the listed company has experienced since the first month of the company's listing to the end of the inspection year. Investors prefer the high book-to-market ratio, high-return stocks, so we construct the control variable $B$-to- $M$ which is book-to market ratio and Return which is the annual stock return rate considering the cash 
dividend reinvestment and removing the impact of cash dividends and reinvestment. We introduce CSI 300 as a dummy variable to reduce the impact. The CSI 300 Stock Index was launched in 2005. From 1996 to 2001, the company which is listed on the Shanghai Stock Exchange use Shanghai Stock Exchange 30 index as a reference. From 2002 to 2004, the reference is Shanghai Stock Exchange 180 index. From 1995 to 2004, the company which is listed on the Shenzhen Stock Exchange use Shenzhen Stock Exchange component index as a reference. If a stock belonging to the index stocks of the corresponding period in the inspection year, the CSI 300 is equal to one, otherwise it is zero. Construct a dummy variable Loss. If the company's net profit is negative, the Loss is equal to one, otherwise it is zero.

To verify the second hypothesis, we construct variables Tobin's $q$ and $\ln (M-$ to- $B)$, the M-to-B is marketto-book. Business revenue and its growth reflect the company's development potential, so we construct variables Revenue which is the 10-logarithmic value of business revenue and Revenue $G S$ which is the revenue growth rate $(\%)$. Considering that investors are concerned about the solvency of the company, we construct a control variable Leverage which is the asset-liability ratio. Moreover, we add the control variable CSI 300 and Age.

\subsection{Descriptive statistics}

Some companies in the selected sample lack the data of some variables. To facilitate demonstration, we delete this part of the sample and delete a few samples with abnormal indicators. In the end, we get 643 different names of listed companies, of which 512 samples contain industry information in their names, and the remaining 131 samples didn't contain. Table 1 presents the descriptive statistics of variables.

Table 1. Descriptive statistics of variables.

\begin{tabular}{|c|c|c|c|c|}
\hline \multirow{2}{*}{ Variable $^{\mathrm{a}}$} & \multicolumn{4}{|c|}{$\begin{array}{c}\text { Subsample of Company Name } \\
\text { without Industry Information }\end{array}$} \\
\cline { 2 - 5 } & $\begin{array}{c}\text { Observ } \\
\text { ations }\end{array}$ & Mean & Median & Minimum \\
\hline Name Score & 131 & 2.37 & 2.28 & 1.52 \\
\hline Shareholders & 1551 & 10.00 & 10.46 & 0.69 \\
\hline Avg Share & 1552 & 9.47 & 8.99 & 0.00 \\
\hline Inst Share & 1259 & 1.82 & 1.76 & 0.00 \\
\hline \multirow{2}{*yyyy}{} & Maximum & $\begin{array}{l}\text { Standard } \\
\text { deviation }\end{array}$ & Skewness & Kurtosis \\
\hline Name Score & 3.89 & 0.45 & 1.35 & 2.44 \\
\hline Shareholders & 13.19 & 2.22 & -2.92 & 8.37 \\
\hline Avg Share & 18.76 & 1.94 & 2.99 & 9.45 \\
\hline Inst Share & 4.50 & 1.27 & 0.16 & -1.08 \\
\hline \multirow{5}{*}{ Variable } & Subsample of Company Name with \\
\cline { 2 - 5 } & \multicolumn{5}{|c|}{$\begin{array}{c}\text { Observ } \\
\text { ations }\end{array}$} & Mean & Median & Minimum \\
\hline Name Score & 512 & 2.57 & 2.51 & 1.42 \\
\hline
\end{tabular}

\begin{tabular}{|c|c|c|c|c|}
\hline \multirow{2}{*}{ Variable $^{\mathrm{a}}$} & \multicolumn{4}{|c|}{$\begin{array}{c}\text { Subsample of Company Name } \\
\text { without Industry Information }\end{array}$} \\
\cline { 2 - 5 } & $\begin{array}{c}\text { Observ } \\
\text { ations }\end{array}$ & Mean & Median & Minimum \\
\hline Shareholders & 4745 & 8.95 & 9.97 & 0.00 \\
\hline Avg Share & 4744 & 10.19 & 9.18 & 6.10 \\
\hline Inst Share & 4324 & 1.81 & 1.89 & 0.00 \\
\hline & Maximum & $\begin{array}{c}\text { Standard } \\
\text { deviation }\end{array}$ & Skewness & Kurtosis \\
\hline Name Score & 4.08 & 0.42 & 0.59 & 0.47 \\
\hline Shareholders & 13.48 & 3.03 & -1.65 & 1.30 \\
\hline Avg Share & 20.50 & 2.58 & 1.81 & 1.79 \\
\hline Inst Share & 4.62 & 1.36 & 0.04 & -1.31 \\
\hline \multicolumn{5}{|c}{ a. Source: Reith Database. (www.resset.cn) } \\
\hline
\end{tabular}

We winsorize some variables including Tobin's $q$, $\ln (M-$ to-B), B-to-M, Revenue $G S$ at the 1st and 99th percentiles, Turnover at the 1st percentiles and Leverage at the 99th percentiles to mitigate the influences of outliers before regression.

\subsection{Empirical model}

The data we collect is unbalanced panel data. We use a fixed-effect model for regression. We construct the following models to verify those two hypotheses:

$$
\begin{gathered}
\text { Inst Recognition }_{i t}=\alpha_{0}+\alpha_{1} \text { Name Score }_{i t}+\alpha_{2} X_{i t}+\varepsilon_{i t} \\
\text { Value }_{i t}=\alpha_{0}+\alpha_{1} \text { Name Score }_{i t}+\alpha_{2} X_{i t}+\varepsilon_{i t}
\end{gathered}
$$

Name Score $_{i t}$ is the explanatory variable in (5) and (6). Explained variable Inst Recognition ${ }_{i t}$ takes the variables Shareholders, Avg Share and Inst Share respectively in (5). Control variable $X_{i t}$ in (5) contains Size, Turnover, Age, B-to-M, Return, CSI 300 and Loss. Explained variable Value $_{i t}$ takes the variables Tobin's $q$ and $\ln (M-$ to$B$ ) respectively in (6). Control variable $X_{i t}$ in (6) contains Revenue GS, Revenue, Leverage, CSI 300 and Age.

\subsection{Empirical results and analysis}

Different companies are listed at different times. The data of earlier listed companies are more than those listed later. Therefore, the data in this paper belong to unbalanced panel data. According to the result of Hausman test, the value of $p$ is 0.00 , we should establish a fixed effect panel model. We divide the sample into two subsamples based on whether or not the company name contains the industry information and then perform regression analysis. Table 2 is the regression result of (5). The data in parentheses are the t-statistic. It can be seen that a $1 \%$ increase in the company's name score is associated with a $3.71 \%$ and $3.95 \%$ increase in shareholders' number of the two subsamples, and the coefficients are statistically significant at the 5\% level and the $1 \%$ level. A $1 \%$ increase in the company's name score is associated with a $0.43 \%$ and $0.45 \%$ increase in per capita shares, a $1.69 \%$ and $1.24 \%$ increase in the shares' proportion held by institutional investors of the two subsamples. In general, 
retail and institutional investors have shown a preference for the company as the company's name score increases. descriptive statistics of variables.

Table 2. Regression result of (5).

\begin{tabular}{|c|c|c|c|c|c|c|}
\hline \multirow{2}{*}{$\begin{array}{c}\text { Vari } \\
\text { able }\end{array}$} & \multicolumn{6}{|c|}{ Explained Variables } \\
\cline { 2 - 7 } & Shareholders & \multicolumn{2}{c|}{ Avg Share } & \multicolumn{2}{c|}{ Inst Share } \\
\hline & $\mathrm{No}^{\mathrm{b}}$ & Yes $^{\mathrm{b}}$ & No & Yes & No & Yes \\
\hline $\begin{array}{c}\text { Name } \\
\text { Score }\end{array}$ & $\begin{array}{c}3.71 \\
(2.26)\end{array}$ & 3.95 & 0.43 & 0.45 & 1.69 & 1.24 \\
$(2.64)$ & $(2.01)$ & $(2.71)$ & $(2.31)$ & $(2.57)$ \\
\hline $\mathrm{R}^{2}$ & 0.53 & 0.59 & 0.50 & 0.47 & 0.50 & 0.45 \\
\hline $\begin{array}{c}\text { F-sta } \\
\text { tistic }\end{array}$ & 63.18 & 210.89 & 57.30 & 129.79 & 54.78 & 61.80 \\
\hline \multicolumn{7}{|c|}{ b. } \\
\hline
\end{tabular}

Table 3 is the regression result of (6). A $1 \%$ increase in the company's name score is associated with a $1.95 \%$ and $1.99 \%$ increase in Tobin's q value of the two subsamples, and both of the coefficients are statistically significant at the $1 \%$ level. A $1 \%$ increase in the company's name score is associated with a $2.1 \%$ and $2.16 \%$ increase in $\ln (\mathrm{M}$-to-B) of the two subsamples, and both of the coefficients are statistically significant at the $5 \%$ level. We can see that an increase in the company's name score will increase the company value. A "good" company name will bring good economic impact to the company.

Table 3. Regression result of (6).

\begin{tabular}{|c|c|c|c|c|}
\hline \multirow{2}{*}{ Variable } & \multicolumn{4}{|c|}{ Explained Variables } \\
\cline { 2 - 5 } & \multicolumn{2}{|c|}{ Tobin's q } & \multicolumn{2}{c|}{$\ln$ (M-to-B) } \\
\hline & No & Yes $^{\mathrm{c}}$ & No & Yes \\
\hline Name & 1.95 & 1.99 & 2.10 & 2.16 \\
Score & $(5.65)$ & $(2.55)$ & $(4.23)$ & $(1.97)$ \\
\hline $\mathrm{R}^{2}$ & 0.40 & 0.40 & 0.47 & 0.42 \\
\hline F-statistic & 37.31 & 103.45 & 49.83 & 110.52 \\
\hline
\end{tabular}

\section{Conclusions}

In a highly competitive stock market, a "good" name is very important to the company. This paper examines how we measure the company name of "good" and "bad", and whether company name affects investor recognition and company value. We construct a set of evaluation system of the company name according to the Chinese way about thinking and Chinese characters from the terseness, smooth, moral and recognition, in addition we have done the empirical research on the relationship between company name, investor recognition and company value. Through the empirical results we find that, if the company name is short, fluent, easy to identify and contains good moral meaning, the company will have more investors, higher per capita shares and higher shares' proportion held by institutional investors. Moreover, if the company name is short, fluent, easy to identify and contains good moral meaning, the company will be more valuable.

This paper suggests that company should consider more of the terseness, smooth, moral and recognition of names when naming or rebranding. It is easy to remember for investors and gain the favor of investors. At the same time, this article can also help investors to rationally understand their investment behavior. The company name doesn't contain the company fundamental information, but it affects investors' decision-making. This kind of vision is not conducive to the development of the stock market. Rational investors should pay more attention to the information that reflects the company's fundamentals. In addition, this paper can also help regulatory authorities manage company names and promote the healthy and sustainable development of the stock market.

\section{References}

1. P. Pensa, SSRN Working Paper, (2006)

2. Y.L. Qiao, Southwestern University of Finance and Economics, (2012)

3. D.M. Oppenheimer, Applied Cognitive Psychology, 20, 139-156 (2006)

4. A.L. Alter, D.M. Oppenheimer, Proceedings of the National Academy of Sciences, 103, 93699372 (2006)

5. G. Huang, Q.F. Fan, Y.F. Zhou, Journal of Beijing University of Posts and Telecommunications, 10, 31-36 (2008)

6. Y. Bao, A.T. Shao, D. Rivers, Journal of Advertising Research, 48, 148-162 (2008)

7. T.C. Green, R. Jame, Journal of Financial, 109, 813-834 (2013)

8. C.J. Fang, Journal of Shanxi University of Finance and Economics, 38, 36-48 (2016)

9. Y.Q. Liu, Nankai Economic Research, 45-56 (2008)

10. M. Cooper, O. Dimitrov, P. Rau, Journal of Finance, 56, 2371-2388 (2001)

11. A. Head, G. Smith, J. Wilson, The Quarterly Review of Economics and Finance, 49, 551-561 (2009)

12. L. Liu, Y.J. Tian, World Economy, 44-50 (2004)

13. G.Z. Li, G.Z. Tang, L. Liu, Manage the World, 40-51 (2011)

14. L.Z. Dai, Southwestern University of Finance and Economics, (2012)

15. Q.J. Yu, B. Zhang, Financial Research, 152-165 (2012)

16. D. Zhang, Beijing Jiaotong University, (2012) 